\title{
Descartes on Mathematical Reasoning and the Truth Principle
}

\author{
John H. Dreher \\ University of Southern California, Trousdale Parkway, Los Angeles, CA, USA \\ Email: dreher@usc.edu
}

How to cite this paper: Dreher, J. H. (2020). Descartes on Mathematical Reasoning and the Truth Principle. Open Journal of Philosophy, 10, 388-410. https://doi.org/10.4236/ojpp.2020.103026

Received: July 29, 2020

Accepted: August 24, 2020

Published: August 27, 2020

Copyright $\odot 2020$ by author(s) and Scientific Research Publishing Inc. This work is licensed under the Creative Commons Attribution International License (CC BY 4.0).

http://creativecommons.org/licenses/by/4.0/

\begin{abstract}
The main purpose of this paper is to examine and assess the plausibility of Descartes' thesis that it is by mathematical reasoning that we ultimately justify the Truth Principle, which is a metaphysical claim. Drawing upon contemporary logic and philosophy of mathematics, the paper argues that Descartes' understanding of mathematical reasoning, especially concerning infinity, enables him to justifiably conclude that the Truth Principle is indubitable.
\end{abstract}

\section{Keywords \\ Truth, Reasoning, Infinity, Natural Light}

\section{Introduction}

During 1648, in his conversation with Burman", Descartes concludes "So proofs in Metaphysics are more certain than those in Mathematics" (Burman, 1648: p. 47f.). Although proofs and hence truths of metaphysics are more "certain" than those of mathematics, the discipline of mathematical reasoning defines correct reasoning everywhere, even in metaphysics. I argue that valid mathematic reasoning for Descartes essentially follows the model established by Euclid, which Descartes amplifies in the algebra of exponential functions (i.e., what we call analytic geometry). According to Descartes' theory of knowledge, every clear and distinct idea perceived by the light of nature is true. Knowledge is the result of "clearly and distinctly perceiving by the light of nature", and mathematical reasoning is clearly perceiving that each step in a sound argument is either intuited directly by clearly and distinctly perceiving it by the light of nature or else follows by clearly and distinctly perceiving by the light of nature that it follows from previous steps. According to the present interpretation, Descartes relies

${ }^{1}$ Cottingham (1976: p. X). 
upon mathematical reasoning to explicate the concept of infinity, which is essentially mathematical. He relies upon the concept of infinity to define the nature of God and goes on to claim that without the notion of infinity, God cannot be conceived because God's nature includes infinite goodness (as well as infinite wisdom and power). Now, the only possible explanation for the fact that we have an idea of God is that God exists; that is because only God has attributes that are sufficiently rich to give us the idea of God. As Descartes explains, the cause of an idea must have as much reality as the content of the idea, and only God could have sufficient reality (i.e., infinite perfections) to give us the idea of an infinite, metaphysical thing. Because God exists, and is infinitely good, powerful, and wise, we know that it is impossible for us to be systematically deceived by a "malicious, evil demon". That implies the so-called "Truth Principle", which is that whatever we clearly and distinctly perceive by the light of nature is true. Now, according to the received semantics of the time, the content of a proposition is not in the least altered if it is prefaced by "it is true that", or "it is affirmed that" or "it is denied that". It follows that if one asserts a proposition $p$, it is the same as asserting that the proposition $p$ is true. Following this (admittedly objectionable principle of Port Royal logic), Descartes concludes from the Truth Principle that the Truth Principle itself is true.

It is at this point that Descartes reasoning is questioned on grounds of circularity. Circularity cannot be avoided because the reasoning that justifies the Truth Principle must itself be clear and distinct reasoning by the light of nature, but we know that this bit of reasoning will yield the truth only if the Truth Principle is itself true, and we certainly cannot reasonably rely upon the Port-Royalist view that just because we have concluded that we are justified in asserting that the Truth Principle is true just because we are justified in asserting the Truth Principle. Admittedly, this is a flaw in Descartes argument; however, three important qualifications must be kept in mind. First, we know that no theory stated in ordinary, natural languages may coherently state its own truth conditions, although conditions on formal languages developed in the $20^{\text {th }}$ century have been more successful, if not entirely uncontroversial ${ }^{2}$. Yet, Descartes did not have the benefit of contemporary logic and semantics; he relied upon the semantics of his own time. Secondly, the mistake that Descartes made is not a mistake that is unique to his theory; it is rather a mistake that is inevitably made by any theory that is set forth in a natural language that states its own truth conditions. Thirdly, the fact that Descartes did err in a way that introduces circularity into his account does not mean that he actually failed to carry out his program. Descartes begins his seminal works Discourse on Method, Meditations on First Philoso-

${ }^{2}$ The problem of stating truth conditions within a formal language is manageable because there is are clear restrictions on legitimate objects of reference. This result is established by formal structures that distinguish between "the object language" from "the meta-language". The semantics of formal languages were initially developed by Tarski. Detailed discussion of truth in formal languages is beyond the scope of this paper, and therefore whether or not Descartes' arguments could be faithfully and fully represented in a formal structure is also beyond the scope of this paper. For a very helpful introductory discussion of this issue see (Beth, 1965: pp. 510-513). 
phy, and Principles of Philosophy by resolving not to accept any proposition that can be doubted and to accept propositions that cannot be doubted. Although Descartes correctly believes that the Truth Principle is indubitable, he nevertheless can doubt the proposition that the Truth Principle is true. What he cannot conceive is that the Truth Principle is true and that its truth can be doubted. In relying upon the Truth Principle, Descartes is remaining faithful to his project, which is to accept only that which is beyond doubt. The crucial caveat is that the fact that Truth Principle is beyond doubt does not prove that it is true.

\section{Clear and Distinct Ideas Perceived by the Natural Light}

Descartes begins Principles of Philosophy with the observation that "there are many preconceived opinions that keep us from knowledge of the truth". $\mathrm{He}$ ventures the thought that the only way to "free ourselves" from those "preconceived opinions" is to doubt "everything which we find to contain even the smallest suspicion of uncertainty" (Descartes, 1644: p. 193). His strategy is to try to reconstruct his knowledge by accepting only that which is absolutely certain and beyond doubt. Famously, the starting point of his grand project is the proposition "Cogito ergo sum". The 1644 program of the Principles of Philosophy is a restatement of the strategy that Descartes defined in Discourse on Method. There Descartes reflects upon his strategy, in effect acknowledging that someone might ask him whether or not his strategy is itself beyond doubt. Descartes' response is the concession that the method that he takes "for gold and diamonds" may be "nothing by a bit of copper and glass". He invites his readers to judge his method for themselves (Descartes, 1637: p. 112).

In Proposition 30 of the Principles of Philosophy Descartes asserts, Descartes reveals basic argument for the Truth Principle is comparatively straightforward: It is that the "light of nature" or "faculty of knowledge" is given to us by God and can never include "any object" that is not true insofar as it is "is encompassed by the faculty of knowledge", which is to say: insofar as it is "clearly and distinctly perceived" (Descartes, 1644: p. 203). This paper begins by attempting to analyze just what Descartes means by "clearly and distinctly perceives", which forces us at this point to take a step back and to deal directly with the possibility that clear and distinct perception, however powerful it supposedly is, just might not be sufficient to remove all doubt, not about everyday perceptions, not about conflating dreams with reality, not about doubting our powers of mind, not even about doubting the paradigm of all knowledge, of mathematics itself.

There are two reasons for all those doubts. The first is that we have "seen people make mistakes in such matters and accept as most certain and self-evident things which seemed false to us". Beyond that Descartes acknowledges that we cannot simply rule out the possibility that the supposedly omnipotent God who created us "may have wished to make us beings of the sort who are always deceived even in those matters which seem to us supremely evident" (Descartes, 1644: p. 194). So, before we may congratulate ourselves for our "clear and dis- 
tinct reasonings" about what is true and what is false. we must first face two doubts about it.

Descartes believes that he can dispose of the first doubt because there are explanations for the fact that others incorrectly believe that they have made discoveries by reason. For example, Descartes argues that the lack of success hitherto enjoyed in subjects like physics is not due to a "defect in (the) power of reasoning", but rather due to our reliance upon imagination rather than upon reason ${ }^{3}$. Presumably, Descartes is here referring to some of the ancient and embarrassing false beliefs that were corrected by the physics of his own time. For example, it is easier to imagine that Earth is stationary, and that the Sun and planets move around it, than it is to imagine that Earth and planets move around the Sun; it is easier to envisage that Sun as setting than that Earth as rising; it is easier to imagine that a heavier cannonball will fall to the ground faster than a lighter cannon ball; it is easier to think that objects that are moving across a flat surface would inevitably stop even if there were no force to stop them than it is to believe that those objects would continue to move across a flat surface forever unless there were a force to stop them. All these ancient beliefs that arose from uncritical imagination were dismantled by the physics that developed in the light of reason during the seventeenth century, the century that ushered in the "Enlightenment". Clear and distinct mathematical reasoning involves collecting data from careful observation and experiment, and then regimenting those data by rigorous mathematical analysis.

It is more difficult to dispel the second source of doubt, which arises from the possibility of an omnipotent God who does not wish us well. Indeed, a malicious God might well trick us so that despite our best efforts, we come to have beliefs that are false. To begin, it is important to understand precisely how a malicious god might deceive us. Is it the case that he might deceive us about what it is to reason well, or is it rather that despite our reasoning well, the beliefs resulting from correct reasoning might nonetheless be false? I shall argue that for Descartes there is only one possible answer. A malicious god could not deceive us about what is clear and distinct reasoning, but he could deceive us in our belief that the products of clear and distinct reasoning are true.

That even God could not deceive us about what is clear and distinct reasoning may seem to have a distinctively anti-Cartesian ring. Yet, the most famous lines in all of Descartes writings confirm that reading. Descartes proclaims: "let him deceive me as he will ... I must finally conclude that this proposition 'I am, I exist' is necessarily true each time I think or conceive it to myself" (Descartes, 1641: p. 17). It may be argued that the Cogito is not really a piece of reasoning from a technical point of view, but the Latin "ergo" in "Cogito Ergo sum" and the equivalent French "donc" certainly suggest that the Cogito is an example, in fact the paradigm, of clear and distinct reasoning in the broader Cartesian sense.

${ }^{3}$ The actual, true God could choose to deceive us about what is correct reasoning, but He certainly would not choose to trick us, because then He would not be acting according to His good, rational nature, and therefore would be an impostor, a malicious god, which is to say, not God at all. 
On the other hand, Descartes explicitly denies that the Cogito is a syllogism with a suppressed major premise like "Everything that thinks is or exists". On the contrary, we know "Cogito ergo sum" by a "simple act of introspection", by which the proposition becomes self-evident (Descartes, 1641a: p. 100). Even so, the standard of introspection raises yet another question: Precisely what is revealed to be self-evident by introspection? It would appear to be impossible to define, but on the other hand, it seems obvious as it is exemplified by the connection that becomes apparent when we carefully consider the proposition " $\mathrm{Co}$ gito ergo sum".

There is a vast literature on the logical analysis of the Cogito, and some of it implausibly rejects the idea that anything at all is self-evident when we affirm the Cogito. Some, in fact, deny that the Cogito even is a claim, much less an argument. In his famous essay "Cogito, Ergo Sum, Inference or Performance", Jaakko Hintikka claims that the "function of the word cogito in Descartes' dictum is to refer to the thought-act through which the existential of self-verifiability of 'I exist' manifests itself' (Hintikka, 1962: p. 129). The fact of one's existence is supposedly exhibited by the fact of one's thinking; in other words, one's existence is revealed in the act of thinking that one exists. As Hintikka claims, "the indubitability of this sentence is not strictly speaking perceived by means of thinking (in the way the indubitability of a demonstrable truth may be said to be); it is indubitable because and in so far as it is actively thought of". In Descartes's argument, the relation of cogito to sum is not of premise to conclusion (Hintikka, 1962: p. 1298).

Alfred Ayer's account is definitely in sympathy with the gist of Hintikka's analysis. For Ayer, "the Cogito" is "degenerate" in the way "in which every statement" that is expressed by the sentence "this exists" is degenerate. Here the demonstrative "points to" the very object whose existence is affirmed. So, one might just as well point to the object affirmed as affirm its existence. The two acts, one of pointing, the other of affirming (or asserting), would convey exactly the same information. The upshot of all this is that "the Cogito" really does nothing more than reveal the information that is conveyed by affirmation of its truth (Ayer, 1956: p. 85f.).

Somewhat later in 1978, Bernard Williams offers a completely different analysis that is supported by several texts from Descartes collected works. According to Williams, "the Cogito" should be understood as a "bare statement of necessity" which can, on Descartes view be intuitively grasped. It derives from the general statement that it is impossible to think without existing, or as Williams understands it: "In order to think it is necessary to exist". According to Williams, the Cogito is the affirmation of one's own existence that is validated by the fact of one's thinking (Williams, 1978: pp. 90-107).

A possible objection to Williams' view derives from Descartes' own denial that "the Cogito" should be affirmed as a syllogism that relies upon a general premise like "Everything that thinks, exists". This would appear to introduce an element of circularity in the argument, if only because the major premise of the syllogism 
would be an existential claim, and the very point of the "argument" is to establish the irrefragable existential claim that he (Descartes), exists. Williams emphasizes that the intuition that it is impossible to think without existence does not entail or even involve an affirmation of the existence of anything (Williams, 1978: pp. 103-105). By the Cogito Descartes means only to affirm a necessary relation between thinking and existence (Descartes 1641a: p. 100).

I believe that it is right to say that subsequent analyses of the Cogito more or less have taken the side of Williams in the grand debate. It is true that one possible difficulty with Williams' approach is that it appears to invoke the assumption that the necessary connection between thinking and existence is just intuited, which may appear to some to introduce an unwelcome subjective element into Descartes' reconstruction of knowledge. Descartes himself resolved not to affirm anything that can be doubted, even in the slightest degree, but perhaps the intuition that it is necessary to exist in order to think is so obvious that it is beyond even the slightest doubt?

In a subsequent essay, E. M. Curley approaches this issue via Descartes' conception of analysis. Curley suggests that Cartesian analysis begins with the affirmation of the simple and the progression from it to the more complicated. This suggests that Descartes may have begun his analysis by seizing upon the intuition that in order for me to think, Imust exist (Curley, 1986: pp. 153-176). Assuming that my thinking necessarily presupposes my existence leads (naturally? reasonably?) to the generalization that in order to think it is necessary to exist. This is a nice result because it takes a natural reading of the Cogito as the starting point, rather than the result of previous analysis. Moreover, the recognition that Descartes' analysis begins with an intuition raises the most important question, which is: What could make an intuition beyond doubt? Descartes answer is that an intuition is beyond doubt if and only if it is clearly and distinctly perceived by the natural light.

\section{Clear and Distinct Reasoning Perceived by the Natural Light}

Descartes was among the great mathematicians, having established the famous Cartesian Coordinates as a model of representing exponential functions. Indeed, no one can doubt the importance that Descartes attaches to mathematical reasoning, but his own words in the Principles of Philosophy (1644) do suggest that mathematics is not primary in his conception of clear and distinct perception. In Proposition 5 of the Principles of Philosophy Descartes admonishes us to remember that even the "demonstrations of mathematics can be doubted" (Descartes, 1644: p. 203). Famously in the first of the Meditations on First Philosophy, Descartes writes: “... since I sometimes believe that others go astray in cases where they think they have the most perfect knowledge, may I not similarly go wrong every time I add two and three or count the sides of a square, or in some even simpler matter" (Descartes, 1641: p. 14). At the very same point, Descartes wonders whether his doubt might be removed by the consideration that God, 
who is supremely good, would not allow us to be deceived in a simple calculation. Yet, Descartes also worries that we might well wonder why it is that God allows us to go wrong in any calculation (Descartes, 1641: p. 14).

It should be emphasized here that Descartes does not claim to have a reason for doubting that the sum of two and three is five, but only for doubting that what appears to us to be forever indubitable might not actually be true. That reason is that we are not yet quite certain that God exists and hence cannot be sure that there is a guarantor who will ensure that what we clearly and distinctly perceive by the light of nature actually is true. The distinction between having a reason for doubting a particular belief and having a reason to doubt our capacity to form true beliefs is crucial. The most important text concerning this issue occurs in Frans Burman's account of his conversation with Descartes, which occurred between April 16 and April 20, 1648 at Egmondae (Cottingham, 1976: p. ixf.). The conversation took up issues from the Discourse on Method, the Meditations on First Philosophy, the Objections and Replies, and finally from the Principles of Philosophy. In the conversation that pertains to the Discourse, Burman refers to a famous paragraph in which Descartes decides upon the method that he should choose in his attempt to determine exactly what it is that we can clearly and distinctly perceive by the. light of nature. He writes that "mathematicians alone have been able to find any demonstrations-that is to say, certain and evident reasonings" (Descartes, 1637: p. 120). Descartes goes on to explain to Burman that mathematical "intelligence, ... is not to be gleaned from books, but rather from practice and skill". As we become more accomplished in mathematical reasoning, we shall become better equipped to investigate other studies (like physics), "since reasoning is the same in every subject" (Burman, 1648: p. 47f.). In this remarkable passage, Descartes is claiming that mathematical reasoning is the paradigm of all clear and distinct reasoning. He further attributes his own success in metaphysics to relentless practice in algebra or what is now called "analytic geometry".

The above passage invites us to distinguish demonstrations or proofs from clear and distinct reasonings. Indeed, in the first part of the passage above, Descartes appears to be claiming that our knowledge of mathematical truths depends upon clear and distinct "reasonings". Here we must carefully distinguish between the acts of demonstration or "clear and distinct reasonings" from the propositions that are demonstrated, which is to say, produced by clear and distinct reasoning. I believe that from Descartes' perspective it is right to think of demonstration as the step-by-step representation of the clear and distinct reasoning. Despite all this, it is nevertheless clear that Descartes believes that even the demonstration of mathematics (which are examples of clear and distinct reasoning) may be doubted.

\section{The Natural Light: Representation and Truth}

We began the previous section, $₫ 3$, by asking the question: What is clear and dis- 
tinct reasoning? Descartes immediately turns our attention to the Cogito, which appears to be or to embody clear and distinct reasoning of some sort. Yet, even a cursory review of the massive literature on Descartes reveals that Descartes' idea of clear and distinct reasoning has been viewed by many distinguished readers as anything but clear and distinct. In fact, Hintikka and Ayer deny that the Cogito is a piece of reasoning at all. Williams affirms that the Cogito is clear and distinct reasoning, but he bases his affirmation on the theory that a general proposition, which is that it is impossible to think without existing, is presupposed by the Cogito. I believe that resorting to a general principle can be a convincing reconstruction of the Cogito, but it hardly seems to remove the Cogito from all doubt. Williams' suggested reading is broadly general, and therefore must claim that more information is contained within it than is contained in the Cogito itself. Curley brings the argument back down to the individual level, but once there we face the very problem that prompted the famous exchange in the first place: Exactly what is the indubitable reasoning that is exemplified by the Cogito? The right answer, I shall argue, is that the Cogito reveals the standard that all reasoning must meet in order to be sufficiently cogent to expunge all doubt. That standard is the standard of clear and distinct reasoning by the natural light. This of course raises yet further questions. Among them, the most important is Just what is the natural light? Unfortunately, Descartes does not provide us with a clear and definitive answer to that question. However, there is much that he claims that suggests a plausible answer.

At the beginning of the third meditation Descartes explicitly considers the nature of thought and the classification of thoughts. He announces that his main concern will be thought of the kind "that can be properly said to be the bearers of truth and falsity". He distinguishes those thoughts (that can be the bearers of truth) from those that are "as it were, the images of things". Thoughts that are the images of things need to be distinguished from thoughts that "induce something more than the likeness of that thing"; which are therefore called "emotions or volitions". Having an image of an ice cream cone becomes something more than a mere thought when we crave the ice cream or, contrarywise, when we are repulsed by it because it is spoiled and sour. Exactly how emotions are to be distinguished from volitions is not taken up at this point, but it is obvious that there is a difference between, say, loving something and intending to do something about the object that is loved, for example, by pursuing or possessing it. The important point is that neither mere images, nor emotions and volitions, are bearers of truth or falsity. Bearers of truth and falsity are thoughts that are called "judgements".

According to Descartes, "ideas, considered in and of themselves", are neither true nor false. If we imagine a "goat or chimera", we imagine each regardless of its actual existence. Mere ideas, which we conceive, are not unlike emotions and volitions, for what we merely conceive need not represent anything. Only judgements are subject to error by misrepresentation; that is thinking that 
something which is false actually is true, or else thinking that something which is true actually is false. Some ideas are ideas of our own invention, but others are forced upon us For example, when sitting by a fire "I feel the heat whether or I want to or not, and this is why I think that this sensation or idea of heat comes to me from something other than myself" (Descartes, 1641: p. 13).

We now have arrived at the central point. When we think that an idea has come to us whether or not we want it, we may rightly say that "nature has taught me to think this". In this case, a "spontaneous impulse" has led me to the belief in the existence of something other than myself that has "transmitted its own likeness to me". This is not to say that its truth has yet been revealed to me by some natural light. In the case of my own existence, what is revealed to me by the natural light is merely that "from the fact that I am doubting, I am certain that I exist". Descartes proclaims that there cannot be an epiphany more certain than one that arises from a "faculty as trustworthy as the natural light". Having "established" and celebrated the natural light, Descartes goes on to explain how it is that we come to know that there actually are things apart from us that cause ideas of them within us. This undertaking is immensely difficult in as much as we constantly find ourselves befuddled by errors deriving from contrary beliefs about what lies outside us. Contradictory inputs imply that blind impulses that result in ideas cannot be the basis of reliable judgment. Reliable judgment must depend upon a guarantor of the accuracy of representation, that is of truth, and that guarantor can only be God! Having concluded that actual knowledge depends upon the beneficence of God, Descartes proceeds to advance his famous argument for the existence of God, which boils down to the claim that the mere fact that he has an idea of God implies that God exists. This bit of reasoning depends upon nothing but "the natural light" because it is "manifest by the natural light that there must be as much <reality> in the efficient and total cause as in the effect of that cause" Since the reality in the idea of the object of God, which is its "objective reality", actually is God, and since the only entity that has reality so great that it is capable of causing the idea of God is God, it inexorably follows that God exists (Descartes, 1641: pp. 24-28).

I believe that this argument is much stronger than many philosophers have thought. It is plausible to think that a cause must be sufficiently strong to account for both the existence and identity of its effect. Thus, the cause of the idea of God must be sufficiently strong to account for the object of the idea, which is God. This, however, does not mean that the argument is beyond criticism, and great philosophers like Gassendi (Gassendi, 1641: pp. 199ff., 251-257) and Hobbes (Hobbes, 1641: p. 127) were quick to focus on its weakest point, which is the claim that we really do have an idea of God. Indeed, many people have thought that "God" is actually a name for something that cannot be conceived, but which is nevertheless sufficiently powerful to account for all that is beyond the pale of human cognition. This of course looks like nonsense and many con- 
temporary philosophers have followed Wittgenstein in his claim that anything that cannot be designated in a straightforward way really cannot have been designated at all, and, to indulge a neologism: the prime example of an "undesignatable" is God (Wittgenstein, 1929: p. 85).

\section{The Natural Light: The Idea of the Infinite}

In any case, we may fairly (though admittedly "creatively") try to capture the essence of Descartes' famous argument for the existence of God argument without directly referring to God. For Descartes, as for Pascal (Pascal, 1670: p. 44), God is "infinite", which raises the obvious question: What could it be within the scope of our finite minds that could possibly give us an idea of "the infinite". Relying upon the principle that the cause must contain as much "reality" as the effect, Descartes would undoubtedly reply that only the infinite can give us the idea of the infinite. Now, since for Descartes, all reasoning is essentially mathematical, it is right at this point to ask how haw we might we come to have the idea of mathematical infinities. According to mathematicians and logicians, there are many levels of infinity: those that are "denumerable" (like the integers and rational numbers) and those that are a level up, like the real numbers, and those that are yet even higher order infinities that are constructed from the reals. We shall begin at the beginning with a denumerable infinity, the positive integers, and then move on to the more complicated case of the real numbers.

Consider the positive integers: the series $1,2,3,4,5,6, \ldots$, and on to "infinity". Now, some philosophers, notably empiricists, will say that it is easy to account for the idea of the denumerable infinity of the positive integers. The trick just to continue the series above and proceed onward; but onward from 6 to what? Well, obviously to 7 and 8 and so on. Of course, some might not "get it" and perhaps for good reason. The "and so on" may be a snare and delusion. Suppose the actual series under consideration is $1,2,3,4,5,6,7,14,15,16,17$, 18, 19 and onward, without end. Cheating! Someone might proclaim, that is not how the series of positive integers go: Your left some out, specifically those from 8 through 13. Ah! That objection presupposes that you already know the series of positive integers, and how, it will be demanded, can you know what is left out of the series without knowing the entire infinite series of the positive integers. But don't be silly, you do not need to know the whole infinite series, you only need to know how to proceed onward from 19. Yet, that cannot be sufficient because the pattern above that ends with 19 might not be repeated or indicate in any way what is to follow. In other words, the very same problem might re-emerge. Perhaps the next fragment of the series unpredictably begins with 48 , skipping the numbers from 20 through 47? The point is that we cannot construct an infinite series from any finite sub-series because however far along we get, there still would be infinitely many unpredictable sub-series that are consistent with the initial finite series. Descartes would surely say at just this point that 
knowing the complete series of integers must be to know the complete denumerable infinity, the infinity of positive integers, and that knowledge cannot be derived from the idea of a finite source. Hence the idea of infinity cannot be constructed by the operations of a finite mind; it must be innate, and furthermore, only something that is infinite, in some sense or other, could possibly have an idea of the infinite to give us.

Someone might argue that all we really need to construct the infinite from the finite is the concept of "going on forever", or more modestly, going on "without limit". From the Cartesian perspective, this move just raises the same old problem. How do we get the idea of "going on forever", or "going on forever in the same manner", or "going on without limit"? All these operations involve infinitely many steps; so, the mental calculation cannot be properly defined without referring to an infinity, which is the idea to explain.

Even so, perhaps it will be insisted that after all, we all somehow "get" the idea of the positive integers, and therefore the arguments about constructing an idea of the infinite from a finite series by "going on forever" cannot be so far wrong. Yet even if this desperate argument is countenanced, it immediately falls apart in the far more difficult cases involving the real numbers, which include the transcendental numbers. These are numbers like $\sqrt{2}$ and $\pi$. Both of these numbers have infinite decimal expansions that are indeterminable, which is essentially to say that their decimal expansions are infinitely long and random. In set theories that are designed to axiomatize arithmetic, the transcendental numbers are accommodated by the Axiom of Choice, which simply posits the existence of the expansions of certain reals like $\sqrt{ } 2$ and $\pi^{4}$.

The existence of transcendental numbers poses a significant epistemological problem from the Cartesian point of view. How can it be that we have knowledge by the "light of nature" of a transcendental number that is designated by an infinitely long random sequence? Surely transcendental numbers are not revealed by anything that could plausibly be described as the natural light by which we understand the Cogito; in fact, transcendental numbers appear to be utterly incomprehensible. However, I believe that Descartes would argue that we do perceive both $\pi$ and $\sqrt{2}$ by the natural light. First, it is by the natural light of mathematical reasoning that we perceive that it follows from the Pythagorean Theorem (which we also perceive by the natural light), that the diagonal of an isosceles triangle with a side of one unit has a diagonal of $\sqrt{2}$ units. It is therefore by the natural light that we draw the conclusion that the ${ }^{4}$ In Prior Analytics, Aristotle refers to a proof of the incommensurability of the diagonal of a right isosceles triangle and its side. The proof depends upon a reductio ad absurdum that purports to show that the opposite supposition that the diagonal is commensurable with its side entails the contradiction that an odd number is even (Jenkinson, 1966: I-23, p. 80). However, the actual proof of incommensurability is attributed by Russell to Euclid. Russell himself produces a simple and elegant reconstruction of Euclid's proof in Introduction to Mathematical Philosophy (Russell, 1919: p. 67).

The extremely difficult proof that $\pi$ is a transcendental number is due to Ferdinand von Lindemann and is definitely beyond the scope of this paper (See von Lindemann, 1882: pp. 213-225). 
diagonal of a right isosceles triangle is incommensurable with its side and hence transcendental. Similarly, we perceive by the natural light that the ratio of every circumference to the diameter of the circle is the same. We call that ratio $\pi$, and we discover that $\pi$ is transcendental by the natural light. which guides von Lindemann's famous proof. Each of these ideas is acquired by clear and distinct mathematical reasoning, which is a sequence of judgments where the last judgment, the conclusion, follows clearly and distinctly by the natural light from the first judgments, called the premises, which are themselves perceived clearly and distinctly by the natural light. Correct mathematical reasoning derives from our nature. It inexorably and infallibly leads us to the conclusion there are transcendental numbers. Transcendental numbers cannot be conceived directly, in and of themselves, by examining their numeric designations (which are random and infinitely long), and yet, we do conceive them.

Of course, many philosophers remonstrate that all this is just nonsense ${ }^{5}$. For example, empiricists have a tell a different story about infinity. So, let us return to the infinite series of positive integers. How, do empiricists account for ideas of them? I believe that the ultimate response of empiricism is to reject the demand for an account. We do not need to account for our knowledge of the series of positive integers if only because we do not have an idea of them, and what is more we do not need an idea of them. All that we need are the resources to go on correctly as far as we need to go. This will give us a good enough idea to pursue our legitimate scientific interests. So, $\pi$ is approximately 3.14 . If that is not close enough for certain purposes, we can continue the calculation until our estimation falls within the margin of acceptable error. We can do the same for $\sqrt{ } 2$. Obviously, however, that will not do for Descartes, because Descartes wants to know how it is possible for any idea to represent accurately, It would seem that the infinite must be grasped all at once, as a completed whole, and it would seem that only an infinite mind could have a conception of the infinite, and that infinite mind, Descartes thinks, can only be God.

\footnotetext{
${ }^{5}$ Russell himself argues that the idea that are infinite collections in this world is a mere assumption. There is no logical reason to think this axiom, which asserts the existence of infinite collections, is true, but neither is there a logical reason to think that it is false (Russell, 1919: p. 77). Note here the phrase "infinite collections in this world". Descartes might well agree that we cannot, for example, prove that there are infinitely many particles in this world. For Descartes, however, numbers are not in this world. There are collections of things in this world that are numbered, but that does not prove or presuppose that numbers are things in this world. It is true that there is some textual evidence for a different reading. In the fifth meditation, Descartes asserts that "it is possible for me to achieve full and certain knowledge of countless matters, both concerning God himself and other things, whose nature is intellectual, and also concerning the whole of that corporeal nature which is the subject matter of pure mathematics". The last part of the quotation seems to imply that pure mathematics includes the study of the nature of corporeal objects. It is certainly true that Descartes thinks that pure mathematics can be applied to the material world because the essence of matter is extension, and pure mathematics describes extension, which is an attribute of matter, but which is not itself corporeal. As Cottingham et al. note, the French version of the Meditations clearly states that the objects of "geometrical demonstration have no concern" with the "existence of corporeal objects" (Cottingham et al., 1984: p. 49).
} 


\section{Clear and Distinct Ideas and the Fruit of Mathematical Reasoning}

As we have concluded, for Descartes the "natural light" or "light of nature" guides us through the process of mathematical reasoning. The results are clear and distinct ideas; they are perceptions that are clearly and distinctly perceived by the natural light. In other words, by the natural light we clearly and distinctly perceive clear and distinct ideas. Descartes' formula ultimately leads to a comparison of the natural light by which we reason with the visual light that enables sight. As Plato reminds us, when we emerge from the cave of conventional, blind ignorance, we are able to perceive objects accurately in the brilliant sunlight, which to say perceive them as they actually are. Descartes explains the point as follows:

I call a perception "clear" when it is present and accessible to the attentive mind-just as we say that we see something clearly when it is present to the eye's gaze and stimulates it with a sufficient degree of strength and accessibility. I call a perception "distinct" if, as well as being clear, it is so sharply separated from all other perceptions that it contains within itself only what is clear (Descartes, 1644: p. 207f.).

To be sure not every "perception" is clear and distinct. We might glimpse a splash of yellow in a far-off bush. It might not be clear to us whether yellow is the color of a bit of foliage or perhaps of a bird's breast or the tail of a small mammal. Sometimes we need to move closer to see precisely what is present. Even so, as Descartes reminds us, even if we are sitting by a fire (rather than in the bright sunlight), there are beliefs that are validated by perception ${ }^{6}$.

To be sure, Descartes goes on to raise doubts about our capacity to distinguish sleeping from waking states, about the effects of diseases that disorder the mind, and crucially about the possibility of systematic doubt. The point is, however, that apart for hyperbolic doubt, there is scarce reason to doubt the testimony of the senses, provided that observation occurs under suitable conditions, for example in the sunlight or by a fire. It is hardly surprising then that Descartes thinks that our knowledge of mathematics is beyond doubt. Consider, for example, the following example of a straightforward demonstration that yields mathematical knowledge.

Thesis: To show that if $(3 \times 5)=(1 / 2 \times x)$, then $(x=30)$.

1) $3 \times 5=1 / 2 \times x$ (antecedent of the conditional to be demonstrated).

2) $2 \times(3 \times 5)=(1 / 2 \times x) \times 2$ (from 1 , Equals multiplied by equals are equal).

3) $2 \times 15=1 / 2 x \times 2$ (from (2) carrying out multiplications within parentheses).

4) $30=2 x / 2$ (from (3), (carrying out multiplication on each side of the equation).

${ }^{6}$ Since this concession by Descartes appears surprising, it is perhaps worthwhile to include the actual text at this point: "Yet although the senses occasionally deceive us with respect to objects that are very small or in the distance, there are many other objects about which doubt is quite impossible, even though they are derived from the sense-for example that I am here, sitting by a fire, wearing a winter dressing-gown, holding this piece of paper in my hands and so on" (Descartes, 1641: p. 13). 
5) Therefore, $30=x$ (from 4 , dividing $2 x$ by 2 and replacing $1 \mathrm{x}$ by $\mathrm{x}$ ).

6) Therefore, if $(3 \times 5)=(1 / 2 \times x)$, then $x=30(\text { from }(1)-(5))^{7}$.

How shall this inference be described? For Descartes we clearly and distinctly perceive each step from (2) to (5) by the natural light by clearly and distinctly perceiving by the natural light that each step from (2) to (5) follows from the preceding step or steps. This is Descartes' model of clear and distinct mathematical reasoning that leads to clear and distinct perceptions by the natural light.

\section{The Port Royalist Theory of the Redundancy of Truth}

It is tempting just to attribute our contemporary understanding of mathematical logic and semantics to Descartes. After all, if Descartes were a contemporary, he ${ }^{7}$ It seems to me that the above proof is exactly the sort of "algebraic" proof that Descartes believes is perceived clearly and distinctly by the natural light and therefore is a good example of the product of clear and distinct reasoning. However, there are other arguments in mathematics that may be sound but are not so easily validated by the natural light. Descartes acknowledges that many arguments require detailed critical analysis and are open to doubt. Only after extensive criticism and revision are finally perceived clearly and distinctly by the natural light. It is not part of Descartes theory that every mathematical question can be easily or definitively settled. He repeatedly acknowledges the need for "practice". Perhaps the following is an example of what would appear to be a simple problem, but which actually is puzzling. It is the problem of accounting for the exponent 0 and, in particular, the problem of finding the value of positive integers that are raised to the exponent 0 .

Suppose that we reason as follows. Any number raised to the first power is equal to that number itself, if only because a number that is raised to an integral exponent $\mathrm{x}$ is multiplied by itself $\mathrm{x}$ times. For example, $\mathrm{N}^{*} \mathrm{~N}{ }^{*} \mathrm{~N}=\mathrm{N}^{3}$. Therefore, it is generally supposed that $\mathrm{N}^{1}=\mathrm{N}$, which raises a very in-

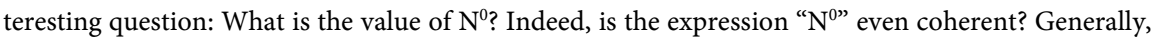
any positive integer raised to the power of zero is deemed to be 1; but why? Perhaps we might argue along the following lines, which emphasize the role of fractional exponents. Observe that for all positive integers $\mathrm{N}, \mathrm{x}: \mathrm{N}^{1 / x}>\mathrm{N}^{1 / x+1}$. Let us illustrate this truth as follows. Let $\mathrm{N}$ be 27 . So, $27^{1 / 1}=27$ (as previously implied). $27^{1 / 2}=5.1961 .27^{1 / 3}=3.0000 .27^{1 / 4}=2.2795 .27^{1 / 5}=1.93318$. Notice that as the denominator of the exponent becomes greater and greater, the exponent itself becomes smaller and smaller. Therefore, it appears that as $\mathrm{x}$ becomes larger and larger, $27^{1 / x}$ will become closer and closer to 1 , but also that it can never go below 1 . It will not go below 1 because any number less than 1 that is multiplied by itself will be less than 1 , and therefore the original positive integer will not be recoverable by the multiplication of its putative roots. Furthermore, the larger $\mathrm{x}$ becomes, the closer $1 / \mathrm{x}$ is to 0 or more precisely, $1 / \mathrm{x}$ approaches 0 as a limit, which appears to be 1 . Finally, every root of 1 is 1. For example, the fifth root of 1 is 1 because $1 \times 1 \times 1 \times 1 \times 1 \times 1=1$. Hence, for all $\mathrm{x}, 1^{1 / \mathrm{x}}=1$. Thus, as the exponent $1 / x$ approaches 0 , the only possible value of $1^{1 / x}$ is 1 . So, we might conclude from all this that any positive integer, $\mathrm{N}$, raised to the power zero is 1 ; in other words, for all positive integers $\mathrm{N}, \mathrm{N}^{0}=1$.

Although this "proof" may be convincing and derive from plausible intuitions, I suggest that it hardly comes up to Descartes' standard of clearly and distinctly perceiving by the natural light. Even if the proof is correct, it relies upon mere intuition rather than solid argument. This is especially true of the extrapolation that is covertly assumed as the value of $\mathrm{x}$ in the exponent $1 / \mathrm{x}$ becomes greater and greater. Intuited extrapolations from examples are not clear and distinct perceptions, they are more like guesses. Furthermore, the above argument totally ignores the fact that positive integers also have roots that are negative. For example, -2 is a square root of 4 , since $(-2 \times-2)=4$. On the other hand, -2 is not a square root of -4 since $-2 \times-2=4$; furthermore 2 is not a square root of -4 , since $2 \times 2=4$. Nevertheless, -2 is a cube root of -8 , since $(-2 \times-2) \times-2=-8$, but -2 is not a fourth root of -16 because $(((-2 \times-2) \times-2) \times-2)=((4 \times-2) \times-2)=(-8 \times-2)=16$. Even so, when it comes to positive integers, roots are relatively well-behaved-meaning, for example, that 2 is a root of 4,8 and 16 . The point of these examples is that even if the conjecture above concerning positive integers is correct, it does not account for the behavior of other integers. Clear and distinct perception by the natural light requires that we have a clear and distinct perception of all objects of a given type (like the integers). Unless we have a fully integrated theory, even plausible first steps cannot be counted as clear and distinct perceptions. 
surely would embrace those formal disciplines and be one of their leading lights. However, we must remember that at the time Descartes wrote, the model of formal logic was the Aristotelian syllogism. Syllogistic logic is virtually useless in any serious proof. For example, syllogistic logic does not include reasoning that depends upon truth-functional operators and connectives. It cannot deal with relations or even identity. In fact, the only model of mathematical reasoning that Descartes had was Euclid. Perhaps the paradigm of clear and distinct mathematical reasoning would have been the Pythagorean Theorem, but Descartes was concerned with even more difficult issues, especially the algebraic representations of conic sections by exponential functions. As we shall see, an attempt at something like formal logic and semantics was made by Arnauld and Nicole, but it was not until the 1680s that their work, Logic or the Art of Thinking, was published-approximately twenty years after Descartes' death. On the other hand, Logic or the Art of Thinking was inspired by Descartes, and much of it is a straightforward attempt to explicate Descartes' own intuitions about logic and semantics.

It is clear that Descartes meant to hold himself to the highest standards in mathematical reasoning and in reasoning about metaphysics, especially about our relation to nature, to each other and above all to God. Because Descartes did not have a robust system of what we call mathematical logic and semantics at his disposal, it is not surprising that he ran into objections about truth and the circular reasoning it appears to encounter, particularly as it stumbles over ancient semantic paradoxes ${ }^{8}$ Even Descartes' most faithful and ardent admirer, Arnauld, is troubled and complains that Descartes has become trapped in a circle of his own making?.

Many philosophers have complained that Descartes' response to Arnauld simply ignores the force of his objection. Descartes' response is that if we clearly and distinctly perceive an idea by the natural light, then we can no longer doubt it. There is, however, one possible exception to this principle. Descartes refers Arnauld to his response to a similar objection found in the second set of replies. There Descartes explains that those who have relied solely on the intellect in their quest for clarity of their "perceptions" are "incapable of doubting them" as long as they "attend to the arguments on which our knowledge of them depends" (Descartes, 1641a: p. 104). This response obviously raises the issue about the certainty of reflections when one is no longer attending to the arguments on which knowledge of them is based. Descartes concedes that until we are certain ${ }^{8}$ These are paradoxes that arise when we concoct sentences that try to state their own truth conditions, like "This is sentence is false", which if true is false, and if false, then true, because what it asserts is the truth that it is false.

${ }^{9}$ Indeed, Arnauld was not one to mince words. He comes directly to the point where he writes: "I have one further worry, namely how the author avoids reasoning in a circle when he says that we are sure that what we clearly and distinctly perceive is true only because God exists. But we can be sure that God exists only because we clearly and distinctly perceive this. Hence before we can be sure that God exists, we ought to be able to be sure that whatever we clearly and distinctly perceive is true" (Arnauld, 1641: p. 150). 
that God exists, we cannot be certain of our memory, which is surely a reasonable claim, but it does not appear to address Arnauld's criticism, which is that we cannot be certain that our conviction that God exists is true until we are certain that whatever we clearly and distinctly perceive by the natural light is true, and we cannot be sure of that until we are sure that God actually does exist. In other words, Arnauld is demanding that Descartes show that whatever we clearly and distinctly perceive is true, but Descartes responds by saying that whatever we clearly and distinctly perceive is indubitable.

Despite appearances to the contrary, I shall argue that Descartes' response to Arnauld is adequate. It is Arnauld who has misconstrued the issue at stake, and it is very significant that after learning Descartes' response, Arnauld appears to have dropped the circularity objection. What is Descartes' defense? The objects of clear and distinct perception by the natural light are clear and distinct ideas. However here we need to be especially careful to distinguish the ideas of things and their qualities and the semantically higher order judgment that certain of those ideas are true. Unfortunately, seventeenth century logic does not always draw a clear distinction between the affirmation of an idea and the affirmation of truth an idea. The logic of the Cartesians of the seventeenth century is attributed mainly to Descartes by Arnauld and Nicole and are laid out in detail by them in their Logic or the Art of Thinking ${ }^{10}$ : In the following crucial lines they carefully explain:

Besides propositions whose subject or attribute is a complex or abstract term, others are complex because they contain terms or subordinate propositions that affect only the form of the proposition, that is, the affirmation or negation that is expressed by the verb... (Arnauld and Nicole, p. 94f.).

The point, as Arnauld and Nicole illustrate, is that if we say that it is true that the earth is round, the comprehensive part of the proposition "It is true that", changes nothing in the meaning of the subordinate part, that is expressed by the verb that occurs in "the earth is round". The same is true if I deny that the earth is round. The work of the subordinate clause is the same, which is expressed by "the earth is round". It follows that if I say that I clearly and distinctly perceive by the natural light that the earth is round, the meaning of "the earth is round remains precisely the same" (Arnauld and Nicole, 1683: p. 95). I shall argue that Descartes is the one who clearly distinguishes between the indubitability of a proposition and its truth, and does acknowledge that what he can demonstrate is not that everything clearly and distinctly perceived by the natural light is true, but rather that nothing that is clearly and distinctly perceived by the natural light can be reasonably doubted because God's existence cannot be reasonably doubted. Of course, that will not be sufficient to satisfy those who doubt God's existence, but it will be enough to satisfy those who are convinced of God's exis${ }^{10}$ The influence of the logic of the Cartesians, the so-called Port Royal logic, extended even to British philosophers, but an exploration of this issue is far beyond the scope of this paper. I mention it here only because the troubles caused by equating the affirmation of an idea and the affirmation of its truth plagues all seventeenth philosophy. 
tence, and Descartes insists that the existence of God cannot be reasonably doubted.

\section{The Truth Principle}

Descartes thinks that the ideal of correct mathematical reasoning is unassailable. A judgment that is a product of clear and distinct reasoning by the natural light is beyond doubt. That, however, raises a "meta-question": Can we demonstrate by clear and distinct reasoning by the natural light that whatever is "proved" by the clear and distinct reasoning of the natural light is true? Toward the beginning of the Discourse on Method, Descartes contemplates this very problem, and he in effect concedes that he may not be able to answer it to everyone's satisfaction, which, indeed has been proved to have been an understatement. In short, Descartes concedes that he does not have a proof that his method guarantees that every idea clearly and distinctly perceived by the natural light is true. But just what is it that stands in his way. What doubt can there be about the matter? The answer, of course, is that we might be systematically deceived. That is why it is that Descartes concludes: "Yet I may be wrong: Perhaps what I take for gold and diamonds is nothing but copper and glass" (Descartes, 1637: p. 112).

What Descartes takes for gold and diamonds is mathematical reasoning, In the Mediations on First Philosophy Descartes famously produces his argument for the existence of God which, if correct, disarms all worries about a malicious demon who deceives us at every step. Descartes offers an argument for the existence of God, but how can that argument be conclusive and rescue the Truth Principle unless we already know that the deliverances that are clear and distinctly perceived by the natural light really are true, which of course is just what is in question. Even so, as I have argued elsewhere, Descartes should not be accused of circularity. Descartes acknowledges that some may reject his reasoning and/or the standards by which he judges reasoning. So, his argument should be charitably viewed as hypothetical: If we can assume that we are not systematically misled, then we can be sure by mathematical reasoning that there is a God who is responsible for what otherwise would appear to be mere good fortune (Dreher, 2017: pp. 202-216).

I believe, just as Descartes concedes, there is not any way to prove that clear and distinct mathematical reasoning will yield truth. But that concession does not end the argument. That is because for Descartes, what makes mathematical reasoning correct is not that it yields the truth, but rather that it yields what cannot be doubted. This fact is often lost in discussions of the Truth Principle in part because of a crucial passage from Meditations.

... since I sometimes believe that others go astray in cases where they think that they have the most prefect knowledge, may I not similarly go wrong every time I add two and three or count the sides of a square, in some simpler matter if that is imaginable (Descartes, 1641: p. 14).

Now, if I doubt that $2+3=5$, the proposition that I doubt is just that $2+3=$ 
5 , which is the very same proposition that I doubt if I doubt that $2+3=5$ is true. But in doubting that $2+3=5$, I do not thereby consider some other proposition to replace it, for example, that $2+3$ really $=6$. The only reason, according to Descartes, for doubting that $2+3=5$ is that we are systematically misled by an evil demon or perhaps by a freakish tendency woven deeply in the nature of things that reinforces false beliefs. As Descartes emphasizes, doubts about clear and distinct perceptions are different in type from ordinary doubts about visual or tactile perception. If I hear a rustling noise at night in my garden, but doubt that it is due merely to the wind, I immediately think of alternatives, for example, that it is an animal, or a thief. Now, Descartes does concede that sometimes it is possible to doubt the product of mathematical reasoning in this sense; that is, it might be that there is an alternative judgment that is more plausible than the initial judgment, but that does not mean that it is possible to doubt just any mathematical proposition. I cannot doubt that $2+3=5$ if only because I firmly believe it and cannot conceive an alternative. Of course, that does not mean that there isn't an alternative; it only means that I cannot conceive it no matter how hard I try.

Now, let us return to the Truth Principle. It cannot be that I both represent myself as clearly and distinctly perceiving a proposition by the natural light and yet doubt that it is true. That is because to doubt that something is true does not in any way change what is doubted. Similarly, the Truth Principle cannot be doubted, but that, of course, does not prove that it is true-it only proves that I cannot doubt its truth. Descartes insists that it will do no good to object to the indubitability of the Truth Principle on the grounds that we have sometimes been mistaken in thinking that we clearly and distinctly perceive. Descartes clearly states that when we come to recognize that we have erred in forming a belief, we also come to see that we did not clearly and distinctly perceive the belief by the natural light in the first place. Indeed, if I come to think that a perception that I once deemed to be clear and distinct may be false, I must also conclude that I did not clearly and distinctly perceive it to be true. What we cannot do is to represent ourselves as having clearly and distinctly perceived a false proposition. Nor can we deem another to have clearly and distinctly perceived a false proposition. In order to do that we would have to represent that proposition to ourselves as both clearly and distinctly perceived and nonetheless false. The mistake I would make in that case would have been to judge knowledge of the truth to be something weaker than clear and distinct perception. The idea that we can doubt what we clearly and distinctly perceive is a delusion.

Descartes very stringent standard by which truth is judged suggests that we ought to reconsider the question as to whether there really are any propositions that we clearly and distinctly perceive to be true by the natural light. Descartes' unequivocal answer is that we clearly and distinctly perceive the cogency of mathematical reasoning by the natural light, and for Descartes mathematical reasoning is ultimately the form of all reasoning, including what Descartes calls 
metaphysical reasoning. That brings us to the metaphysical proof of the existence of God in the third meditation. The essence of Descartes' proof is that only God could give us the idea of God because only God could be the source of the idea of infinite, and as we have already seen, we grasp the idea of infinity by mathematical reasoning. According to Descartes, once we know that God exists, we know that there cannot be systematic doubt because it cannot be both that what we clearly and distinctly perceive is indubitable and yet that we doubt its true. It is only then that we know that what we clearly and distinctly perceive by the natural light is not only indubitable but also that the claim that it is true is also indubitable, which emphatically is not to say that the claim that it is true is itself true.

\section{Summary of the Main Argument}

We know that if God exists, then the Truth Principle is true. And we cannot doubt the existence of God because we cannot doubt that we have an idea of infinity which is derived from clear and distinct mathematical reasoning, for example, that there is an infinity of positive integers and that there also are "infinitely expansible" numbers that are transcendental, like $\sqrt{ } 2^{11}$. It is true that some empiricists will complain that we really do not even have an idea of infinity; all that we really mean by an infinite series is finite series "that continues forever". Yet as we have discovered, there are important objections to this empiricist line of thought. In the first place, we really cannot tell from any series of finite integers just how to continue them, which is to say that an initial finite series does not determine a unique successor series. Moreover, even if a finite series did determine a unique successor series, we could not carry it out. The best we could do is to say that we would need to carry the series on forever, meaning without end. But the concept of carrying on indefinitely, without end, obviously requires the concept of infinity itself. So, ultimately the empiricist view must be that although we do not have a "positive" idea of infinity, we do have a "negative" idea of infinity. Yet, at least according to Descartes, infinity is not a negative concept. Indeed, in the case of the transcendental numbers we grasp the concept of infinity directly, for example, as the ratio of the circumference of a circle to its diameter or as the ratio of the diagonal of a right isosceles triangle to its side.

None of this actually overcomes the circularity objection to the Truth Principle, but it does defang it, and therefore it no longer undermines Descartes project. While it is true that Descartes' putative argument for the Truth Principle

${ }^{11}$ In mathematics the existence of denumerable and higher order infinities are asserted by two infinity axioms, one that Axiom of Infinity, which asserts the existence of the rational numbers, and the second, which we call the Axiom of Choice and which asserts the existence of denotation the real numbers (including the transcendentals). Higher order infinities are generated from the infinity of the reals by the powers set operation (Russell, 1919: pp. 63-88). One may claim that these axioms are not clearly and distinctly perceived by the natural light, but I do not think Descartes would agree. That is because these axioms are presupposed by the truth of familiar mathematical principles (for example by the algebra of the conic sections without which we could not even state the principles that describe the motion of the planets). 
is circular, it is also true that no Cartesian can reasonably doubt the Truth Principle, and that, remember, is Descartes self-imposed standard for dealing with the construction of knowledge. Recall how the Meditations on First Philosophy begins. Descartes resolves to "devote himself sincerely", to the demolition of his previous opinions, but he immediately cautions that it is not "necessary for me to show that all my opinions are false". What reason demands, he continues, "is to hold back my assent from opinion which are not completely certain and indubitable". That means that assent is to be withheld when there is "reason for doubt" (Descartes, 1641: p. 12).

The key point is that Descartes does not find a reason to doubt mathematical reasoning, which presupposes the concept of infinity ${ }^{12} \mathrm{He}$ does not doubt that in order to have the concept of infinity (from mathematical reasoning) it must be that God exists. Further he finds it to be impossible to doubt that whatever he clearly and distinctly perceives is true provided that God exists. So, he finds it impossible to doubt the Truth Principle, which therefore is justified by his own standard, which is to affirm all and only what he clearly and distinctly perceives by the natural light. The key phrase here is "by his own standard"-not by the standard of Hobbes or Gassendi, or even by the standard of Arnauld, but rather by his own standard, which Descartes concedes, may be deemed by others to be mere copper and glass, but which for him surely is gold and diamonds.

\section{Conclusion, Limitations and Suggestions for Further Research}

The conclusion of this paper is that Descartes did successfully finish his project for the reconstruction of his knowledge and that he therefore was in a position to sort out just what is commended by reason and what he had been taught by unreliable authorities. His project depends upon his view that mathematical reasoning is indubitable, and that mathematical reasoning presupposes the idea of infinity, which could only be derived from an infinite mind, which is to say the divine mind. This is does not mean that Descartes has proved his thesis and forced agreement by those who disagree with him about what is dubitable. But then again, Descartes does not claim to satisfy anyone else, he seeks only to satisfy himself and to share his good epistemological fortune with those who care ${ }^{12}$ It might be objected here that Descartes should have distinguished a "qualitative" from a "quantitative" conception of infinity. Indeed, if we think of something as infinitely good or powerful or wise, we do not seem to be making quantitative judgments. I believe, however, that Descartes would insist that at bottom, all references to infinity must be reduced to quantitative judgments. That is essentially what it means to say that metaphysical reasoning is subordinate to mathematical reasoning. Perhaps it will be readily granted that this view is plausible when it comes to space and time. Space and time are measured quantitatively; so, if we say that Euclidean space is infinite, we must mean that its measuring stick must contain infinitely many marks. But what are the marks by which we measure infinite goodness or wisdom or power? Aren't those "infinities" qualitative? Even so, good deeds can be counted, both with respect to frequency and comparative value, as can the number and comparative significance of truths that are known and finally as well as by the comparative potency and frequency of acts of will. Without some form of measurement, goodness, knowledge, and power are essentially incomparable. It is right to attribute this type of view to scientifically-minded early moderns like Descartes. 
to take notice of it. The centrality of mathematical reasoning and its indubitability drives Descartes' arguments through his Meditations on First Philosophy and his replies to his critics. However, it is only in his final conversation with Burman that he flatly and unequivocally insists that mathematical reasoning is the foundation of all reasoning, including metaphysical reasoning ${ }^{13}$.

There are at least two ways in which this contribution is limited. First, it is limited because we ourselves find the concept of infinity difficult to grasp and consequently ever slipping away from our conceptual grip. On the other hand, it was the clear-headed, the tough-minded Bertrand Russell who demonstrated that arithmetic as we know it (basically what is central to Newtonian physics), can be axiomatized within ordinary set theory and logic with two additional principles: the Axiom of Infinity and the Axiom of Choice (Russell, 1919: pp. 63-88). The second way in which this discussion is limited concerns Descartes' text. In the replies to his critics, he often seems to become impatient with criticism. There are far too many examples of this to detail here, but in this connection, it will perhaps be helpful to remember his voluntarism. Descartes' final position is that what is true is true because God wills its truth, and that God even could have willed contradictions to be true (Descartes, 1641: pp. 290-292). Indeed, although Descartes does not doubt that what is clearly and distinctly perceived by the natural light is true, he is completely open to the thought that not everything that is true can be clearly and distinctly perceived by the natural light-at least not by us humans. This thought, I believe, is an expression of Descartes' exasperation with his critics, even to the point of deeming their complaints to be insincere. After all, did those critics really mean to claim that what they clearly and distinctly perceive might be false after all, and if so, is that because they clearly and distinctly perceive that what they clearly and distinctly perceive might be false? Did they really mean that they doubted reasoning itself, even the reasoning that led them to think that what they clearly and distinctly perceive may nonetheless be false?

Finally, it is my hope that this paper will stimulate further scholarly work about the thinking of philosophers during the early modern period about the nature of truth and the importance of "mathematical reasoning". Of course, further research includes not only the Cartesians but also empiricists like Locke and Hume, and idealists like Kant. It also includes Newton as well as the rationalists who followed Descartes, especially Leibniz, who prepared the way for Gauss, Lobachevsky, and other great mathematicians of the nineteenth century.

\section{Conflicts of Interest}

The author declares no conflicts of interest regarding the publication of this paper.

${ }^{13}$ In this respect Descartes clears the way for Pascal, who also recognizes the importance of the concept of infinity for understanding the divine, but contrary to Descartes, insists that God and the infinite are really matters of faith if only because the mind cannot bring itself to accept or to reject the conception of the infinite on a rational basis (Pascal, 1670: §XVI, 226-253; pp. 64-73). 


\section{References}

Arnauld, A. (1641). Fourth Set of Objections. In J. Cottingham et al. (Eds.), The Philosophical Writings of Descartes (Vol. II, (1984), pp. 138-153). Cambridge: Cambridge University Press. https://doi.org/10.1017/CBO9780511818998.019

Arnauld, A., \& Nicole, P. (1683). La logique ou l'art de pensser. In A. Antoine, P. Nicole, \& J. Buroker (Trans. and Eds.), Logic or the Art of Thinking (5nd ed., p. 94f). Cambridge: Cambridge University Press.

Ayer (1956). I Think, Therefore I Am. In W. Doney (Ed.), Descartes: A Collection of Critical Essays (pp. 81-87 (1967)). New York: Doubleday \& Company. (Reprinted From: Ayer, A.J., The Problem of Knowledge, New York, St. Martin's Press, Inc., pp. 45-54)

Beth, E. (1965). The Foundations of Mathematics (2nd ed., pp. 510-513). Amsterdam: North-Holland Publishing Co.

Burman, F. (1648). Conversation with Burman. In J. Cottingham (Trans. and Ed.), Descartes' Conversation with Burman, 1976 (pp. xif, 47f.). Oxford: Clarendon Press.

Cottingham, J. (Trans. and Ed.) (1976). Descartes' Conversation with Burman (pp. xif, 47f). Oxford: Clarendon Press.

Cottingham, J. et al. (1984). The Philosophical Writings of Descartes (Vol. I, pp. 111-151, 192-193). Cambridge: Cambridge University Press.

Curley, E. (1986). Analysis in the Meditations: The Quest for Clear and Distinct Ideas. In A. Rorty (Ed.), Essays on Descartes' Meditations (pp. 153-176). Berkeley, CA: University of California Press. https://doi.org/10.1525/9780520907836-010

Descartes, R. (1637, 1984). Discourse on Method. In J. Cottingham et al. (Eds.), The Philosophical Writings of Descartes (Vol. I, pp. 111-151). Cambridge: Cambridge University Press.

Descartes, R. (1641, 1984a). Meditations on First Philosophy. In J. Cottingham et al. (Eds.), The Philosophical Writings of Descartes (Vol. I, pp. 3-62). Cambridge: Cambridge University Press.

Descartes, R. (1641a, 1984a). Second Set of Replies. In J. Cottingham et al. (Eds.), The Philosophical Writings of Descartes (Vol. II, pp. 87-92). Cambridge: Cambridge University Press. https://doi.org/10.1017/CBO9780511818998.016

Descartes, R. (1644, 1984). Principles of Philosophy. In J. Cottingham et al. (Eds.), The Philosophical Writings of Descartes (Vol. I, pp. 193-292). Cambridge: Cambridge University Press.

Dreher, J. (2017). The Circle, from Descartes Point of View. Open Journal of Philosophy, 7, 202-216.

Gassendi, P. (1641, 1984a). Fifth Set of Objections. Second Set of Replies. In J. Cottingham et al. (Eds.), The Philosophical Writings of Descartes (Vol. II, pp. 199ff, 251-257). Cambridge: Cambridge University Press.

Hintikka, J. (1962). Cogito Ergo Sum: Inference or Performance. The Philosophical Review, Vol. LXXI, No. 1. In W. Doney (Ed.), Descartes: A Collection of Critical Essays (pp. 108-130). New York: Doubleday \& Company.

Hobbes, T. (1641, 1984a). The Third Set of Objections. In J. Cottingham et al. (Eds.), The Philosophical Writings of Descartes (Vol. II, pp. 121-137). Cambridge: Cambridge University Press.

Jenkinson, A. J. (trans.) (1966). Aristotle Stagiritis Son of Nicomachus. In R. McKeon (Ed.), Prior Analytics (c.350 BCE). The Basic Works of Aristotle (pp. 65-109). New 
York: Random House.

Pascal, B. (1670). Pensées. In P. Blaise, \& H. Levi (Trans., Eds.), Pensées and Other Writings (pp. 5-181, (1995), pp. 1-181). New York: Oxford University Press.

Russell, B. (1919). Introduction to Mathematical Philosophy (pp. 63-96). London: George Allen and Unwin, Ltd.

von Lindemann, F. (1882). Uber die Zahl $\pi$. Mathematische Annalen, 20, 213-225. https://doi.org/10.1007/BF01446522

Williams, B. (1978). "The Certainty of the Cogito". In Doney, Willis, ed., Descartes: $A$ Collection of Critical Essays, (1967), Garden City, New York, Anchor, Doubleday \& Company, pp. 88-107.

Wittgenstein, L. (1929). Lecture on Ethics. In S. Cahn, \& J. Haber (Eds.), Twentieth Century Ethical Theory 1995 (pp. 81-87). Englewood Cliffs, NJ: Prentice Hall. 